Engineering

Electrical Engineering fields

Okayama University

Year 2000

Circuit configurations and performance of the active common-noise canceler for reduction of common-mode voltage generated by voltage-source PWM inverters

Satoshi Ogasawara

Okayama University
Hirofumi Akagi

Tokyo Institute of Technology

This paper is posted at eScholarship@OUDIR : Okayama University Digital Information Repository.

http://escholarship.lib.okayama-u.ac.jp/electrical_engineering/41 


\title{
Circuit Configurations and Performance of the Active Common-Noise Canceler for Reduction of Common-Mode Voltage Generated by Voltage-Source PWM Inverters
}

\author{
Satoshi Ogasawara* and Hirofumi Akagi** \\ *Department of Electrical Engineering, Okayama University \\ 3-1-1 Tsushima-naka, Okayama, 700-8530 JAPAN \\ ${ }^{* *}$ Department of Electrical Engineering, Tokyo Institute of Technology \\ 2-12-1 O-okayama, Meguro, Tokyo, 152-8552 JAPAN
}

\begin{abstract}
This paper discusses two different circuit configurations of the active common-noise canceler (ACC) which has been proposed by the authors. One is characterized by its dc power supply isolated from the dc link of a PWM inverter. The configuration makes it possible to integrate the ACC with a medium-voltage PWM inverter. The other compensates a partial frequency component of the commonmode voltage. The purpose is not to achieve complete cancellation, but to restrict only a slope in a change of the common-mode voltage applied to an ac motor. As a result, the core size of the common-mode transformer used in the ACC becomes small considerably. Experimental results show good effects of the proposed active circuits on both ground current and conducted EMI.
\end{abstract}

\section{INTRODUCTION}

In recent years, the development of high-speed power semiconductor devices such as insulated gate bipolar transistors (IGBT's) has realized high response and high efficiency in voltage-source pulse-width-modulation (PWM) inverters. However, high-speed switching can lead to the following serious problems: 1) ground current escaping through stray capacitors [1], [2]; 2) conducted and radiated electromagnetic interference (EMI) [3]-[7]; 3) bearing current and shaft voltage $[8]-[10] ; 4)$ shortening of insulation life of motors and transformers [11], [12]. A steep change in voltage and/or current at a switching operation of the inverter produces high-frequency oscillatory common-mode and differential-mode currents because parasitic stray capacitors inevitably exist inside an ac motor.

A common-mode choke or EMI filter, which consists of only passive elements, has been used to solve these problems. Recently, it has been attempted to eliminate the common-mode voltage or current by using active elements [13]- [17]. These methods are classified into two categories from a viewpoint of operation of the active elements. One is that each active element acts as a switch, thus leading to achieving high efficiency [13]-[15]. However, it is difficult to obtain complete elimination, because switching characteristics such as rise time and delay time of the phase voltage at an inverter output terminal depend on amplitude and polarity of the inverter output current. The other is that the active elements act as a linear amplifier [16], [17]. The linear operation leads to an excellent elimination, although the active elements consume a small amount of electric power.

The authors have proposed an active common-noise canceler (ACC) using an active circuit which acts as a linear amplifier. The ACC superposes a compensating common-mode voltage on an inverter output to eliminate the common-mode voltage produced by the inverer. As a result, the common-mode voltage applied to a load is canceled completely [17].

This paper proposes two different circuit configurations for the ACC. One is characterized by its dc power supply isolated from the dc link of a PWM inverter. The configuration makes it possible to integrate the ACC with a medium-voltage PWM inverter. The other compensates a partial frequency component of the common-mode voltage. The purpose is not to achieve complete cancellation, but to restrict only a slope in a change of the common-mode voltage applied to an ac motor. As a result, the core size of the common-mode transformer used in the ACC becomes small considerably. Experimental results show good effects of the proposed active circuits on both ground current and conducted EMI.

\section{Active Common-noise Canceler}

\section{A. Configuration and Principle}

Fig. 1 shows the configuration of an experimental system including the active common-noise canceler (ACC) which has been proposed by the authors [17]. A voltage-source PWM inverter using IGBT's drives an induction motor of $3.7 \mathrm{~kW}$ through three feeder wires, and the motor frame is connected to an earth terminal on a switch board. Measurement of conducted EMI is performed by using a LISN and a spectrum analyzer. The ACC is connected between the inverter output terminals and the three feeder wires. It consists of the following elements: a push-pull emitter follower using two bipolar junction transistors having complementary symmetry, a common-mode transformer [2], three capacitors to detect the common-mode voltage appearing at the inverter output terminals, and two dc-side capacitors to prevent a dc current from flowing in the additional winding of the common-mode transformer. 


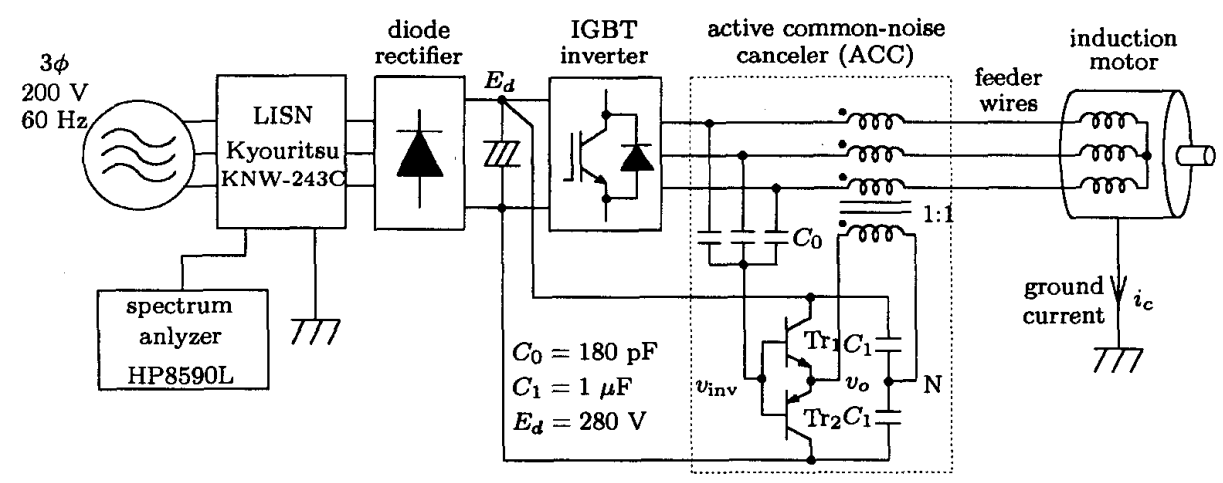

Fig. 1. The original configuration of active common-noise canceler (ACC).

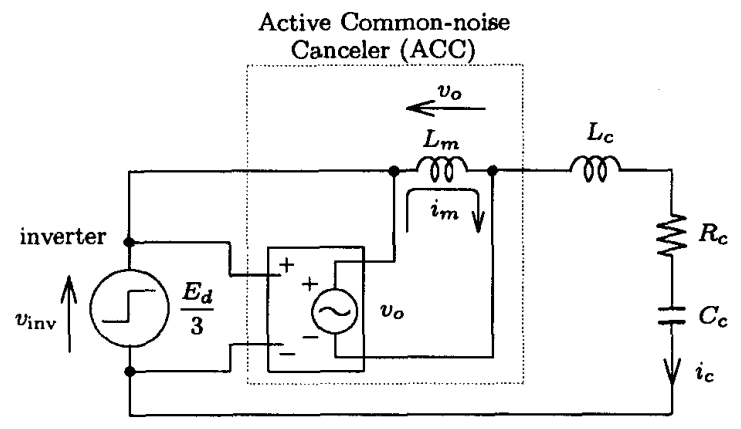

Fig. 2. Common-mode equivalent circuit.

A common-mode current $i_{c}$ flows to the earth terminal through stray capacitors between the windings and frame of the motor, because a zero-sequence output voltage of the inverter, i.e., a common-mode voltage, changes at every switching operation of the inverter. The ACC is connected for the purpose of canceling this common-mode voltage perfectly, so that no common-mode current flows, i.e., $i_{c}=0$.

Fig. 2 shows a common-mode circuit equivalent to the experimental system [2]. Here, $C_{c}$ means the stray capacitor between the motor windings and the frame, and the total common-mode inductance and resistance are shown as $L_{c}$ and $R_{c}$, respectively. In the equivalent circuit, the voltage-source inverter is modeled by a step voltage source $v_{\text {inv }}$, because switching operation in one phase of the inverter causes a step change in the common-mode voltage by $1 / 3$ of the dc link voltage. If no ACC is connected, the step change causes an oscillatory common-mode current $i_{c}$ flowing into the earth terminal.

The combination of a voltage-controlled voltage source and an inductor, which are surrounded by a dotted line, forms to the ACC. The emitter follower, along with the three capacitors, is represented as the voltage-controlled voltage source due to the following characteristics: a voltage gain close to unity, a high input impedance, and a low output impedance. On the other hand, the common-mode transformer is the same as a conventional common-mode choke, except for connecting a tightly coupled additional winding (secondary winding) to the output of the emitter follower. Therefore, the common-mode transformer is expressed as a magnetizing inductor $L_{m}$ in the equivalent circuit, neglecting the leakage inductances.

The purpose of the Y-connected capacitors in Fig. 1 is to detect the common-mode voltage produced by the inverter. The emitter follower applies the same voltage as the detected voltage to the common-mode transformer. The three primary windings of the common-mode transformer with the polarity shown by the dots in Fig. 1 are connected between the output terminals of the inverter and the feeder wires. Therefore, the polarity of the compensating voltage $v_{\mathrm{o}}$ is opposite to that of the inverter common-mode voltage $v_{\text {inv. }}$. As a result, cancellation of the common-mode voltage is performed perfectly, and so no common-mode current flows.

\section{B. Effects of the $A C C$}

Fig. 3 shows actually measured waveforms of a commonmode voltage and a ground current when no ACC is connected. At every switching time of the inverter, a stepwise change occurs in the common-mode voltage $v_{\text {inv }}$ and an oscillatory common-mode current $i_{c}$ flows to the grounding conductor through stray capacitors between the windings and frame of the motor with a rated current of $20 \mathrm{~A}$. The peak value and oscillation frequency of the common-mode current approximate $0.7 \mathrm{~A}$ and $300 \mathrm{kHz}$, respectively. Although this common-mode current seems to be negligible, it may cause conducted EMI. Fig. 4 shows waveforms of a common-mode voltage and a ground current with connecting the ACC. It is shown that the ACC can suppress the ground current almost perfectly, because the ACC cancels the common-mode voltage produced by the inverter. 


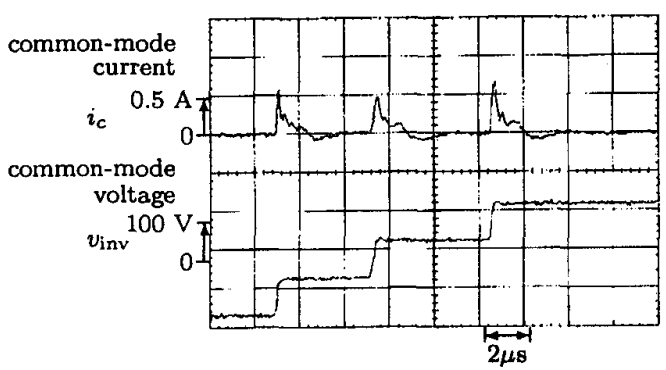

Fig. 3. Common-mode current when no $\mathrm{ACC}$ is connected.

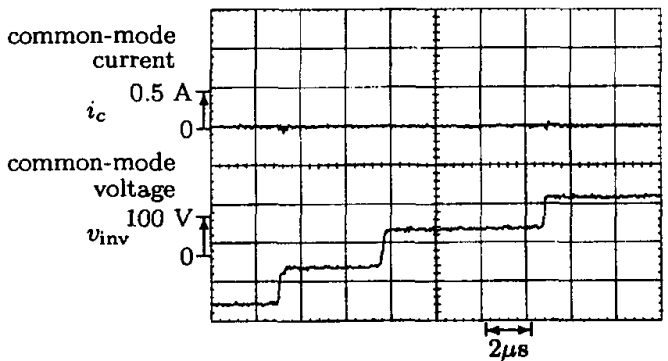

Fig. 4. Common-mode current when the original ACC is connected.

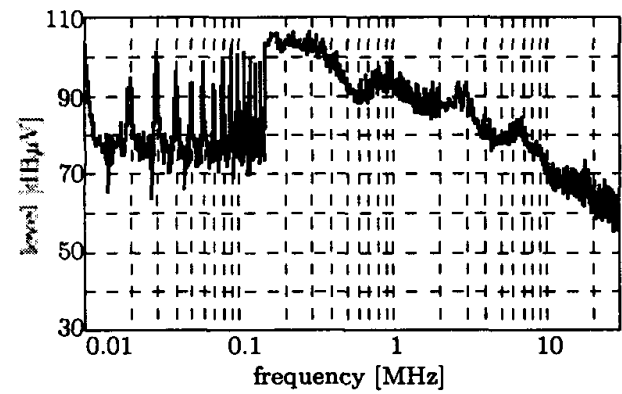

Fig. 5. Conducted EMI when no ACC is connected.

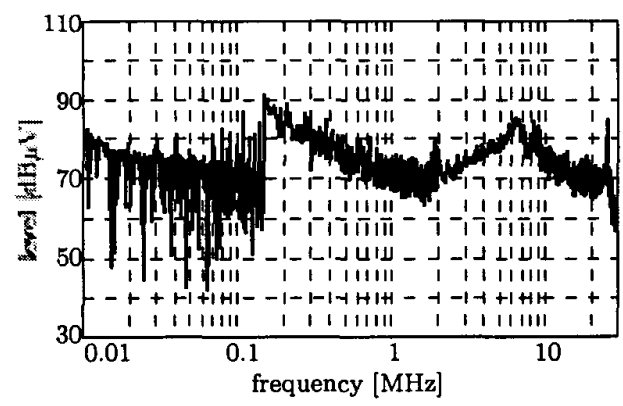

Fig. 6. Conducted EMI when the original ACC is connected.

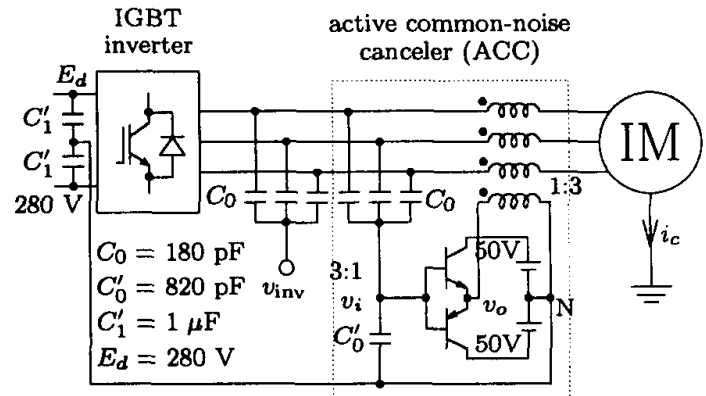

Fig. 7. ACC with dc power supply separated from the inverter.

Figs. 5 and 6 show spectra of conducted EMI when the ACC is connected or not. The oscillation in the commonmode current appears in the spectrum of Fig. 5 as a peak around $300 \mathrm{kHz}$. In a frequency range lower than $150 \mathrm{kHz}$, impulse spectra exist at intervals of $10 \mathrm{kHz}$ which is a carrier frequency of the PWM inverter. Meanwhile, Fig. 6 indicates that the conducted EMI is reduced in a wide frequency range up to $5 \mathrm{MHz}$ by $20 \mathrm{~dB}$ at the maximum

In reference [17], the effect of the ACC on prevention of electric shock has been confirmed by using a measuring circuit complying with a Japanese standard. Moreover, the ACC is also a promising way of reducing motor shaft voltage and bearing current.

\section{ACC with DC Supplies Separated from INVERTER}

In the original ACC shown in Fig. 1, the dc link voltage is used as dc power supplies of the emitter follower circuit. Therefore, it is required that the rated voltage of complementary transistors used in the emitter follower circuit is higher than the dc link voltage. Since the input voltage of the three-phase diode rectifier is $200 \mathrm{~V}$ in Fig. 1, the emitter follower circuit consists of the complementary transistors rated at $400 \mathrm{~V}$. However, complementary transistors with a rated voltage exceeding $400 \mathrm{~V}$ are difficult to obtain from the market. As a result, the original ACC is not applicable to an inverter with a dc link voltage higher than $400 \mathrm{~V}$.

\section{A. Circuit Configuration}

Fig. 7 shows a new configuration of the ACC with separated power supplies. The proposed ACC (hereafter referred to as separete-type ACC) is characterized by using dc power supplies $( \pm 50 \mathrm{~V})$ separated from the dc link voltage of the inverter.

When the common-mode transformer for superposing a common-mode compensating voltage onto the inverter output has a turn ratio of $1: n$, a supply voltage higher than $E_{d} / n$ is enough to cancel the common-mode voltage. This selection of the turn ratio makes it possible to apply the separete-type ACC to an inverter with a dc link voltage higher than the rated voltage of complementary transistors. 


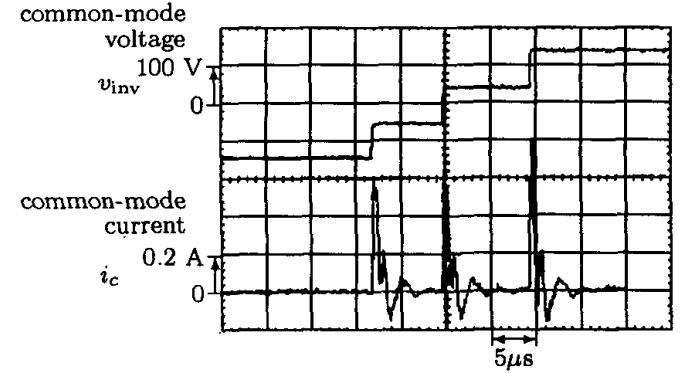

Fig. 8. Common-mode current when no ACC is connected. common-mode

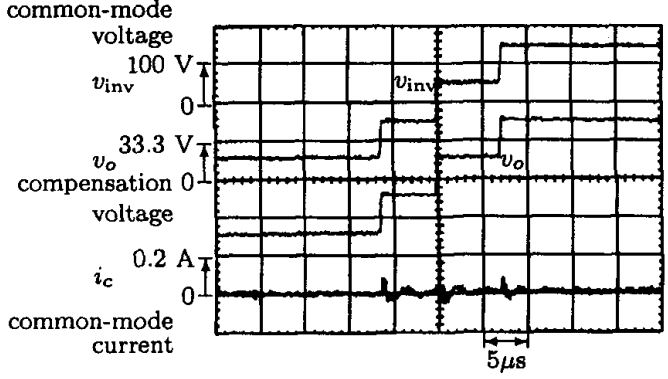

Fig. 9. Common-mode current when the separate-type ACC is connected.

Note that the magnetizing current of the common-mode transformer, which is supplied from the emitter follower circuit, increases by $n$ times. In the experimental system, the turn ratio of the common-mode transformer is set to 1:3. For this reason, the ratio of the potential divider consisting of $C_{0}$ and $C_{0}^{\prime}$ is required to be $1 / 3$. Experimentally, $C_{0}^{\prime}$ is adjusted to $820 \mathrm{pF}$, taking an input capacitance of the emitter follower circuit into consideration, though the theoretical value of $C_{0}^{\prime}$ is $6 C_{0}=1080 \mathrm{pF}$.

Moreover, the other $\mathrm{Y}$-connected capacitors are connected to the output terminals of the inverter for measurement of the inverter common-mode voltage $v_{\text {inv }}$. Since the capacitance of these $\mathrm{Y}$-connected capacitors is nearly equal to the IGBT output capacitance used in the inverter, direct connection of the capacitors to the inverter output terminals does not cause any problem. In the experimental system, the dc link voltage is $280 \mathrm{~V}$, because the input terminals of the diode rectifier are connected to a three-phase voltage supply of $200 \mathrm{~V}$. Therefore, the supply voltage of the emitter follower circuit is selected as $\pm 50 \mathrm{~V}$.

\section{B. Effect on Ground Current and Conducted EMI}

Fig. 8 shows waveforms of a common-mode voltage and a ground current when no ACC is connected. The waveforms are almost the same as that of Fig. 3. Fig. 9 shows the common-mode current when the separete-type ACC proposed in this paper is connected between the inverter output terminals and the feeder wires. It is shown that the separete-type ACC can suppress the common-mode current almost perfectly. The experimental result implies that the effect of the separete-type ACC is almost the same as that of the original one, even though the voltage applied to the emitter follower circuit is decreased. The remaining common-mode current is generated by a small difference between the common-mode voltage at the inverter output terminals and the output voltage of the separete-type ACC. It is considered that the difference is caused by a time delay of the complementary transistors and the mismatching between the ratio of the potential divider and the turn ratio of the common-mode transformer. However, the commonmode current is suppressed sufficiently.

Fig. 10 shows a spectrum of the conducted EMI when no ACC is connected. The spectrum looks like the same as that of Fig. 5, and it has a peak at $300 \mathrm{kHz}$ which is the resonant frequency of the common-mode current. Fig. 9 shows an effect of the separete-type ACC on the conducted EMI. It is confirmed that the separete-type ACC reduces the conducted EMI in a wide frequency range under $2 \mathrm{MHz}$. Especially in a frequency range from $10 \mathrm{kHz}$ to $150 \mathrm{kHz}$, the conducted EMI of Fig. 9 is $20 \mathrm{~dB}$ smaller than that of Fig. 10 at the maximum. However, the effect of the separete-type ACC proposed in this paper is not as good as that of the original ACC as shown in Fig. 6. The following is required to obtain a good reduction:

- to minimize the mismatching between the ratio of the potential divider and the turn ratio of the commonmode transformer;

- to improve frequency characteristics of the emitter follower circuit;

- to reduce leakage inductance in the common-mode transformer.

\section{ACC FOR COMPENSATION OF PARTIAL FREQUENCY COMPONENTS}

The original ACC has a theoretical advantage in that it can cancel common-mode voltage perfectly. A voltagesource inverter generates a common-mode voltage including the following components:

1. high-frequency components caused by high $d v / d t$ of the common-mode voltage at a switching time;

2. middle-frequency components consisting of harmonics related to the switching frequency of the pulse-widthmodulation (PWM);

3. low-frequency components consisting of harmonics related to the inverter output frequency.

For example, a space vector modulated inverter produces low-frequency components of the zero-sequence voltage, i.e., common-mode voltage, at multiples of 3 of the fundamental frequency [18]. If the ACC compensates all the frequency components, the size of the common-mode transformer mainly determines the volume of the ACC. The linkage flux of a winding in the common-mode transformer is equal to time integral of the voltage induced in the winding. Compensation of the lower frequency components requires a larger common-mode transformer. However, since only 


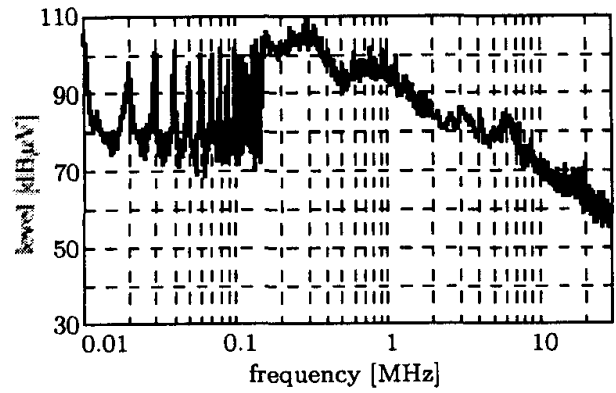

Fig. 10. Conducted EMI when no ACC is connected.

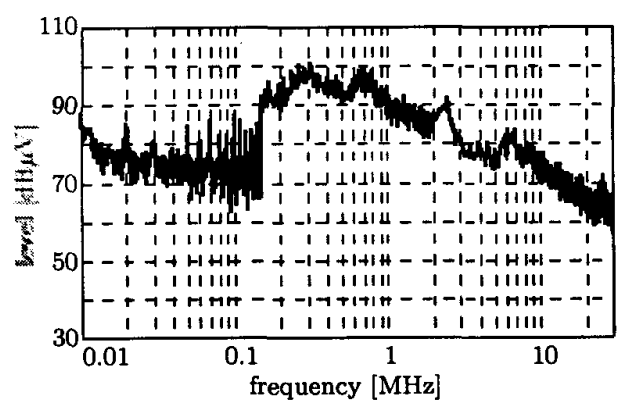

Fig. 11. Conducted EMI when the separate-type ACC is connected.

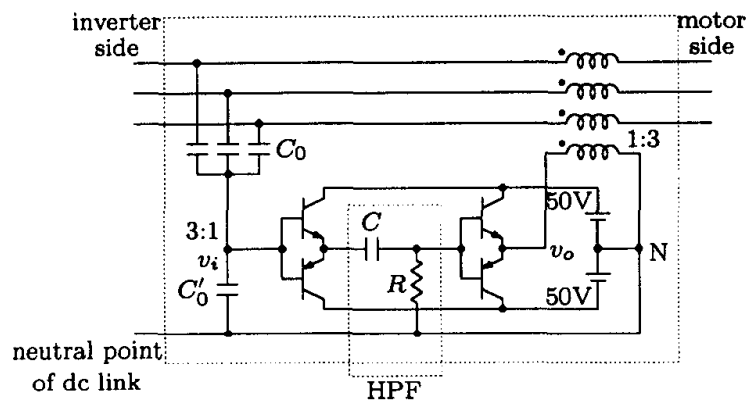

Fig. 12. ACC for compensation of partial frequency components of common-mode voltage.

the high-frequency components caused by high $d v / d t$ at the switching time exerts a bad influence upon the ground current and the conducted EMI, limitation of compensation to high-frequency components is effective in minimizing the core size of the common-mode transformer.

\section{A. Circuit configuration}

Fig. 12 shows another type of ACC for compensation of partial frequency components, proposed in this paper. The purpose of the ACC (hereafter referred to as partialtype ACC) is, not to achieve complete cancellation, but to restrain only a slope in change of the common-mode voltage applied to the motor. The partial-type ACC is characterized by insertion of a high-pass filter (HPF) between two emitter follower circuits, although this circuit is similar to the separete-type ACC in dc supplies separated

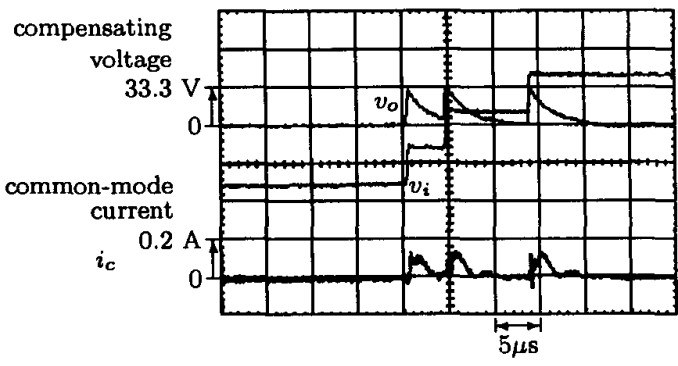

Fig. 13. Common-mode current $(R C=1.6 \mu \mathrm{s})$.

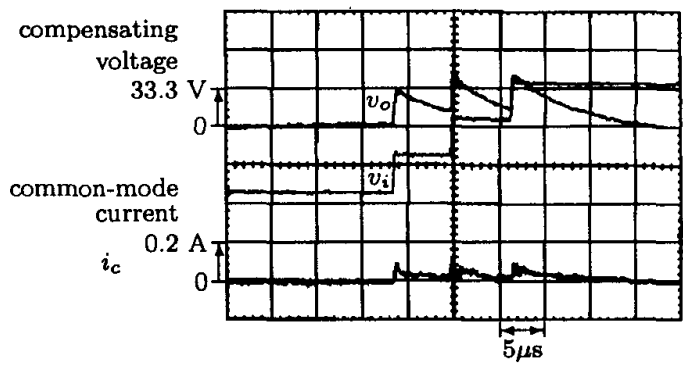

Fig. 14. Common-mode current $(R C=4.7 \mu \mathrm{s})$.

from the dc link voltage as shown in Fig. 7. The potential divider of $1 / 3$, which consists of capacitors of $C_{0}$ and $C_{0}^{\prime}$, detects the common-mode voltage at the inverter output terminals, and the HPF extracts the high frequency component caused by the high $d v / d t$ from the detected common-mode voltage. Finaly, by using the common-mode transformer, the extracted voltage is superposed on the inverter common-mode voltage. As a result, it is possible to restrict the steep change in the common-mode voltage applied to the motor, so that the common-mode or ground current can be reduced considerably.

\section{B. Compensation Characteristics}

Figs. 13 and 14 show waveforms of the common-mode current in the cases that the time constants of the HPF are set to $1.6 \mu \mathrm{s}$ and $4.7 \mu \mathrm{s}$, respectively. It is shown that the common-mode current is reduced to $1 / 6$ or $1 / 10$ by the partial-type ACC, compared with the case that no ACC is connected as shown in Fig. 8. Here, $v_{i}$ and $v_{o}$ mean the input and output waveforms of the emitter follower circuits in the partial-type ACC. Note that the amplitudes of the actual inverter common-mode voltage and the actual superposed compensating voltage are three times as large as $v_{i}$ and $v_{o}$ in Figs 13 and 14, respectively.

Figs. 15 and 16 shows spectra of the conducted EMI with the partial-type ACC, the time constant of which is selected as $1.6 \mu \mathrm{s}$ or $4.7 \mu \mathrm{s}$, respectively. As the time constant is set to be longer, the common-mode current becomes smaller. The reason is that the partial-type ACC compensates wide-frequency components when the time constant is set to a large value. Here, the time constants of $1.6 \mu \mathrm{s}$ and 


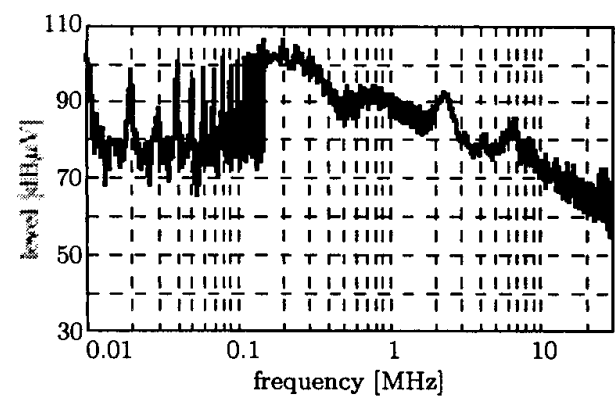

Fig. 15. Conducted EMI $(R C=1.6 \mu s)$.

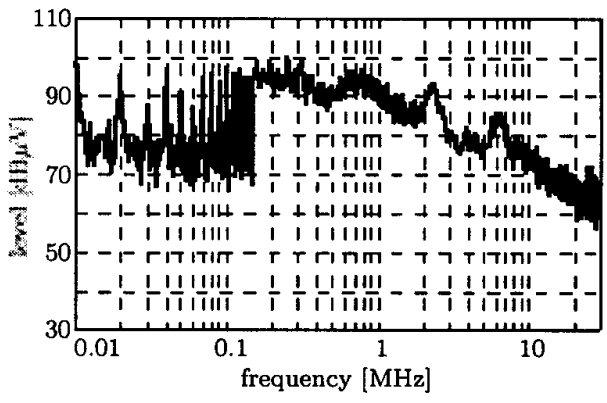

Fig. 16. Conducted EMI $(R C=4.7 \mu \mathrm{s})$.

$4.7 \mu$ s correspond to the cutoff frequency of $100 \mathrm{kHz}$ and $33 \mathrm{kHz}$, respectively. The conducted EMI in a frequency range lower than the cutoff frequency is the same as that in Fig. 10, because the partial-type ACC compensates only the high-frequency components including in the commonmode voltage. As the time constant is set to be longer, the larger core of the common-mode transformer is necessary. However, the linkage flux of the common-mode transformer in the case of $4.7 \mu \mathrm{s}$ is reduced to $1 / 5$, compared with that of the ACC which cancels the common-mode voltage completely as mentioned below.

\section{Time Constant and Core Size}

Fig. 17 illustrates waveforms of the common-mode voltages and interlinkage flux of the common-mode transformer used in the partial-type ACC. From the top to the bottom, the waveforms mean the common-mode voltage at the inverter output terminals, the common-mode voltage generated by the partial-type ACC through the commonmode transformer, the common-mode voltage applied to the load, and the interlinkage flux inside the commonmode transformer, respectively. This figure assumes that lower or upper three IGBTs in the three-phase inverter are switched simultaneously. In this case, the inverter generates the maximum common-mode voltage. Since the HPF extracts the high-frequency component from $v_{\text {inv }}$, the common-mode voltage produced by the partial-type ACC

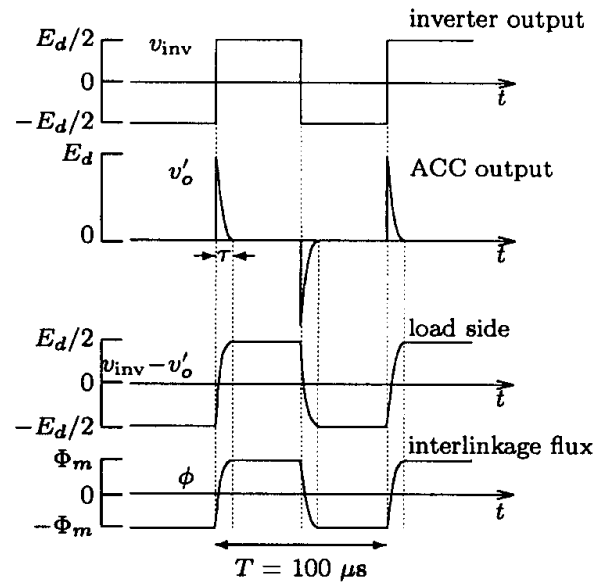

Fig. 17. Interlinkage flux of common-mode transformer (partial-type $\mathrm{ACC}$ ).

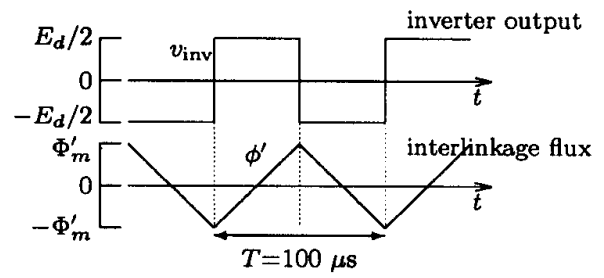

Fig. 18. Interlinkage flux of common-mode transformer (ACC).

through the common-mode transformer is given by

$$
v_{o}^{\prime}=E_{d} e^{-\frac{t}{\tau}}
$$

where $\tau$ means the time constant of the HPF. The voltage difference between $v_{\text {inv }}$ and $v_{o}^{\prime}$ is applied to the inverter load. As a result, the partial-type ACC can reduce the steep change in the common-mode voltage applied to the load. Core size of the common-mode transformer has a relation to the maximum interlinkage flux which is the time integral of $v_{o}^{\prime}$. The maximum interlinkage flux $\Phi_{m}$ is proportional to the time constant as follows:

$$
\Phi_{m}=\frac{1}{2} \tau E_{d}
$$

Therefore, the smaller the time constant, the smaller the core size.

On the other hand, Fig. 18 shows the interlinkage flux of the original ACC which perfectly cancels the commonmode voltage generated by the inverter. In this case, the maximum interlinkage flux $\Phi_{m}^{\prime}$ is determined by the PWM period of the inverter.

$$
\Phi_{m}^{\prime}=\frac{1}{2} E_{d} \frac{T}{4}
$$

As shown in Fig. 14, the partial-type ACC provides a good performance in reducing the common-mode current, 
when the time constant of the HPF is selected as $4.7 \mu$ s, i.e., $1 / 21$ of the PWM period. Since the maximum interlinkage flux of the partial-type ACC is reduced to $1 / 5$ of that of the original ACC, thus making core size of the common-mode transformer small considerably.

The partial-type ACC can not cancel all the frequency components of the common-mode voltage produced by the inverter, but can compensate for the high-frequency components higher than the cutoff frequency of the HPF, thus contributing to applying the middle- and low-frequency components of the common-mode voltage to the load. The common-mode voltage has a strong relation to motor shaft voltage as described in [17]. The partial-type ACC has little capability of reducing the shaft voltage, although it can reduce the common-mode current. Therefore, one of the most effective ways to completely reduce the shaft voltage accompanied by bearing current is the original ACC rather than the partial-type ACC.

On the other hand, the waveform of $v_{\text {inv }}-v_{\circ}^{\prime}$ in Fig. 17 is the same as that of the common-mode voltage applied to the load when a common-mode transformer (CMT) [2] is connected. This fact implies that the CMT and the partial-type ACC have the same effect on the commonmode voltage and current. Since the damping resistor connected to the secondary winding of the CMT and the stray capacitors of the load determine the time constant of the common-mode circuit, the partial-type ACC has the following advantages over the CMT:

- Performance in restricting slope of the common-mode voltage is independent of the stray capacitance;

- Design of the ACC does not require any line inductance or stray capacitance value of the common-mode circuit in advance.

\section{Conclusions}

This paper has proposed a new ACC with dc power supply isolated from the dc link of an inverter. The configuration makes it possible to integrate the ACC with a midium-voltage PWM inverter, the dc-link voltage of which is higher than the rated voltage of complementary transistors used in the ACC. A prototype ACC with dc power supplies of $\pm 50 \mathrm{~V}$ is designed and constructed for an IGBT inverter with a dc link voltage of $280 \mathrm{~V}$. The experimental results show that the proposed ACC has almost the same performance of reducing the common-mode current and conducted EMI as that of the original ACC.

Furthermore, this paper has proposed another ACC intended for compensating partial frequency components. Experimental results demonstrate that the ACC can reduce both ground current and conducted EMI, taking such an advantage that the core size of the common-mode transformer is decreased to $1 / 6$ compared with that in the original ACC for compensating all the frequency components.

\section{REFERENCES}

11 Y. Murai, T. Kubota, and Y. Kawase: "Leakage Current Reduction for a High-Frequency Carrier Inverter Feeding an Induction Motor," IEEE Trans. Industry Applications, vol. 28, no. 4, pp.858-863, Jul./Aug., 1992.

[2] S. Ogasawara and H. Akagi: "Modeling and Damping of HighFrequency Leakage Currents in PWM Inverter-Fed AC Motor Drive Systems," IEEE Trans. Industry Applications, vol. 32, no. 5, pp. 1105-1114, 1996.

[3] M. A. Jabbar and M. A. Rahman: "Radio Frequency Interference of Electric Motor and Associated Controls," IEEE Thans. Industry Applications, vol. 27, no. 1, pp. 27-31. Jan./Feb., 1991

[4] G. Venkataramanan and D. M. Divan: "Pulse Width Modulation with Resonant dc Link Converters," IEEE Trans. Industry Applications, vol. 29, no. 1, pp. 113-120, Jan./Feb., 1993.

[5] E. Zhong and T. A. Lipo: "Improvement in EMC Performance of Inverter-Fed Motor Drives," IEEE Trans. Industry Applications, vol. 31, no. 6, pp. 1247-1256, 1995.

[6] S. Ogasawara, H. Ayano, and H. Akagi: "Measurement and Reduction of EMI Radiated by a PWM Inverter-Fed AC Motor Drive System," IEEE Trans. Industry Applications, vol. 33, No. 4, pp. 1019-1026, Jul./Aug., 1997.

[7] G. L. Skibinski, R. J. Kerkman, and D. Schlegel: "EMI Emissions of Modern PWM ac Drives," IEEE Industry Applications Magazine, vol. 5, no. 6, pp. 47-81, Nov./Dec. 1999.

[8] S. Chen, T. A. Lipo, and D. Fitzgerald: "Modeling of Motor Bearing Currents in PWM Inverter Drives," IEEE Trans. Industry Applications, vol. 32, no. 6, pp.1365-1370, 1996.

[9] J. M. Erdman, R. J. Kerkman, D. W. Schlegel, and G. L. Skibinski: "Effect of PWM Inverters on AC Motor Bearing Currents and Shaft Voltages," IEEE Trans. Industry Applications, vol. 32, no. 2, pp. 250-259. Mar./Apr., 1996.

[10] D. Busse, J. Erdman, R. J. Kerkman, D. Schlegel, and G. Skibinski: "Bearing Currents and Their Relationship to PWM Drives," IEEE Trans. Power Electronics, vol. 12, No. 2, pp. 243-252, Mar., 1997.

[11] A. von Jouanne, D. A. Rendusara, P. N. Enjeti, and W. G. Gray: "Filtering Technique to Minimize the Effect of Long Motor Leads on PWM Inverter-Fed AC Motor Drive Systems," IEEE Thans. Industry Applications, vol. 32, no. 4, pp. 919-926, 1996.

[12] A. von Jouanne, P. N. Enjeti, and W. G. Gray: "Application issues for PWM Adjustable Speed AC Motor Drives," IEEE Industry Applications Magazine, vol. 2, no. 5, pp. 10-18, Sep./Oct. 1996.

[13] A. L. Julian, G. Oriti, and T. A. Lipo: "Elimination of CommonMode Voltage in Three-Phase Sinusoidal Power Converters," IEEE Trans. Power Electronics, vol. 14, No. 5, pp. 982-989, Sep., 1999.

[14] A. von Jouanne, and H. Zhang: "A Dual-Bridge Inverter Approach to Eliminating Common-Mode Voltage and Bearing and Leakage Currents," IEEE Trans. Power Electronics, vol. 14, No. 1, pp. 43-48, Jan., 1999.

[15] M. Cacciato, A. Consoli, G. Scarcella, and A Testa: "Reduction of Common-Mode Currents in PWM Inverter Motor Drives," IEEE Trans. Industry Applications, vol. 35, no. 2, pp. 469-476, 1999.

[16] I. Takahashi, A. Ogata, H. Kanazawa, A. Hiruma: "Active EMI Filter for Switching Noize of High Frequency Inverters," Proceeding of the PCC-Nagaoka, pp. 331-334, 1997.

[17] S. Ogasawara, H. Ayano, and H. Akagi: "An Active Circuit for Cancellation of Common-Mode Voltage Generated by a PWM Inverter," IEEE Trans. Power Electronics, vol. 13, No. 5, pp. 835-841, Sep., 1998.

[18] H. van del Broeck. H. C. Skudelny, and G. V. Stanke: "Analysis and Realization of a Pulsewidth Modulator Based on Voltage Space Vectors," IEEE Trans. Industry Applications, vol. 24, No. 1, pp. 142-150, Jan./Feb., 1988. 